Original Research Article

\title{
Pharmacoeconomics of allergic rhinitis drugs treatment in tertiary care hospital
}

\author{
Sanjeeva Kumar Goud Thandu ${ }^{1}$, A. N. Vijay Kumar ${ }^{2}$, Rahul Rajendra Kunkulol ${ }^{1}$
}

${ }^{1}$ Department of Pharmacology,

Pravara Institute of Medical

Sciences, Loni (BK),

Maharashtra, India

${ }^{2}$ Department of Pharmacology,

Vitthalrao Vikhe Patil

Foundation's Medical College,

Ahmednagar Maharashtra, India

Received: 13 August 2019

Revised: 16 September 2019

Accepted: 17 September 2019

*Correspondence to:

Sanjeeva Kumar Goud Thandu,

Email: thandusanjeeva@

gmail.com

Copyright: (C) the author(s), publisher and licensee Medip Academy. This is an openaccess article distributed under the terms of the Creative Commons Attribution NonCommercial License, which permits unrestricted noncommercial use, distribution, and reproduction in any medium, provided the original work is properly cited.

\begin{abstract}
Background: Allergic rhinitis also called hay fever; it is a very common in India. Harmless exposing substances cause an allergic reaction. Allergic rhinitis is of the two types, one is the seasonal occurred with the change of seasons, second is the perennial means any time during the year.

Methods: This was a cross-sectional study to determine the cost analysis allergic rhinitis drugs used in treatment of ENT OPD in a tertiary care teaching hospital, Kamothe, Navi Mumbai. The patients were interviewed; prescriptions were analyzed number of medicines prescribed.

Results: Incidence of polypharmacy two drugs per prescriptions were prescribed 140 and three drugs per prescriptions 60 . In the total number of 200 prescriptions, the cost of 43 prescriptions were in between 251-300 Indian rupees and 18 prescriptions were 301-350 Indian rupees. Patient knowledge about the drug use in this study, out of 200 pts $37 \%$ of allergic rhinitis patients knew the correct dosage of the prescribed drugs while $63 \%$ were not aware.

Conclusions: Majority of the participants drugs were prescribed two to three drugs, per prescription cost was high because all the drugs prescribed by brand name and no drugs were prescribed by generic name. Improvement in knowledge about generic medicines is important factor to prefer generic medicine. Reduction in cost of drug will improve compliance.
\end{abstract}

Keywords: Allergic rhinitis, Cost analysis, Generic medicine

\section{INTRODUCTION}

A general and progressive increasing medical care cost is a matter of concern for patients as well as for policymakers and health service providers. Every year over a hundred million people are dragged into poverty due to increasing the cost of medical bills. In many countries, every year an increasing percentage of the population is forced into poverty as they have to spend the money on health services. The millions of people suffering due to a lack of access or inability to afford medical care. According to the world health organization annual World Health Report 2010 reflects that health and medical service is a limited resource for an unlimited demand, between twenty percentages to forty percentage of all health expenditure money is wasted because of inefficiency and overpaying is a type of waste. In some countries, the costs of medicine are up to sixty-seven times higher than the international average price. This over expenditure grossly affects expenditures for other health services. Every year, directly or indirectly medical costs have been dragging millions of Indian populations get into poverty. ${ }^{1}$ Cost analysis is a type of partial pharmacoeconomic evaluation which compares the costs of two or more alternatives without regard to outcome . $^{2,3}$ There are different types of brands and the same drug are the alternatives available in the market for a patient, this 
is expected to provide a same therapeutic outcome. Analysis of their costs can highlight the phenomenon of 'inter-brand price variation' which can put the substantial financial burden on patients along with posing moral and ethical concerns. ${ }^{4}$ Allergic rhinitis is common in India, this is considered as a common condition with a high morbidity, and is associated with reduced quality of life due to its coexistence with other diseases (such as chronic sinusitis and asthma) and is a cause of substantial medical care expenditures. ${ }^{5,6}$ The present study was undertaken to study the cost analysis of drugs used in the treatment of allergic rhinitis at tertiary care hospitals in the outpatient ENT department at MGM Medical College, Navi Mumbai, India. The objectives of the study were to find out the incidence of polypharmacy drugs or prescriptions, Evaluation of cost per prescriptions, study patient knowledge about the drug use.

\section{METHODS}

\section{Study type}

This was a cross-sectional and observational study.

\section{Study place}

The present study was conducted at ENT OPD in MGM hospital, at Kamothe, Mumbai.

\section{Ethical approval}

The study was approved by the MGM Institutional ethics committee.

\section{Study period}

The duration of the study was six months (16 August 2014 to 16 February 2015).

\section{Selection criteria of the patients}

According to the inclusion and exclusion criteria, those who attended and who had suffered from allergic rhinitis 200 patients were recruited from the ENT outpatient department.

\section{Inclusion criteria}

All the patients of allergic rhinitis, adult patients between 18-60 years, patients of either sex, patients willing to participate in study and were ready to give written informed consent.

\section{Exclusion criteria}

Pregnancy patients, patients suffering from genetic disorders, patients on chronic medications other than allergic rhinitis drugs and patients who were not willing to participate in this study were excluded from the study.

\section{Study procedure}

The patients, after taking their written informed consent, were interviewed regarding their knowledge regarding use of drugs prescribed. The parameters of prescriptions were recorded. All the prescriptions were analyzed on number of medicines prescribed in generics, duration of therapy and written instructions to the patients regarding dose and dosing interval of the drug.

\section{Statistical analysis}

The data were subjected to the descriptive statistical analysis used by Microsoft Excel and presented as a percentage.

\section{RESULTS}

Polypharmacy was observed in 200 prescriptions. Three drugs were prescribed in 60 prescriptions, while two drugs or prescriptions were prescribed in 140 prescriptions. The total number of drugs prescribed per prescription was 3.16 .

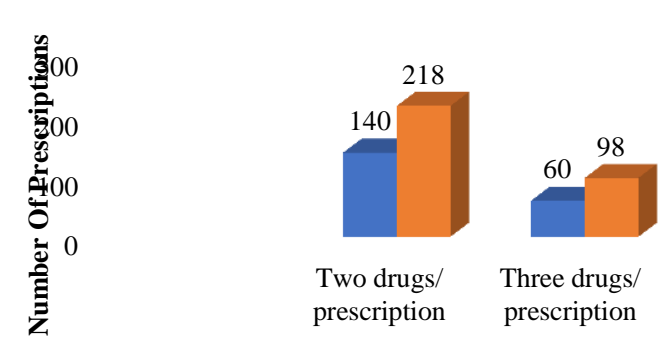

Number Of Drugs Per Presciption

No. of prescriptions (200) $\square$ Total Number of drugs(316)

Figure 1: Incidence of polypharmacy.

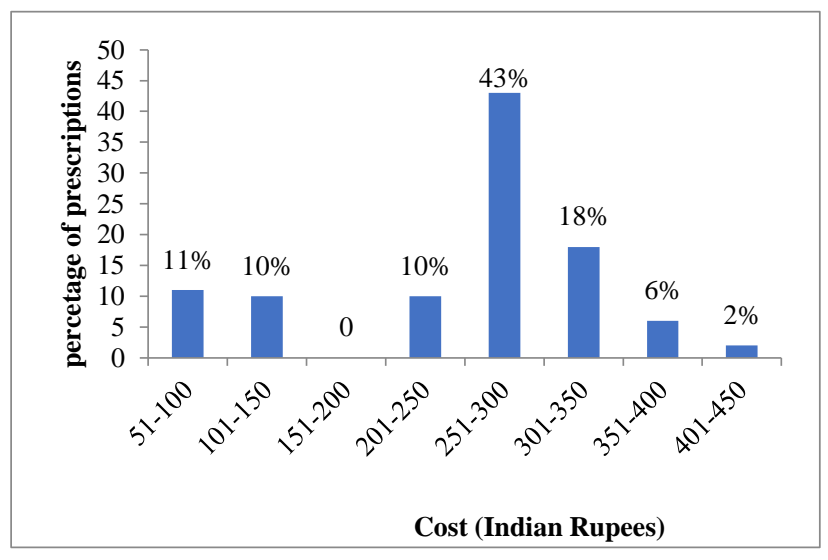

Figure 2: Cost analysis.

Cost of the prescriptions was calculated considering only the cost of the drugs. Of the 200 prescriptions, the cost of 
most of the prescriptions $(43 \%)$ was in the range of 251 300 Indian rupees followed by $18 \%$ in the range of 301 350 Indian rupees.

Table 1: Patient knowledge about the drug use.

\begin{tabular}{|l|l|}
\hline $\begin{array}{l}\text { Patient knowledge } \\
\text { about the drug use }\end{array}$ & $\begin{array}{l}\text { Number of allergic } \\
\text { rhinitis patient }\end{array}$ \\
\hline Aware & $126(63)$ \\
\hline Not aware & $74(37)$ \\
\hline
\end{tabular}

Patient knowledge about the drug use in this study, out of 200 patients $37 \%$ of allergic rhinitis patients knew the correct dosage of the prescribed drugs while $63 \%$ were not aware.

\section{DISCUSSION}

Drugs play a very important role in health protection and recovery from disease. Around one -third of the world, population has difficulties in accessing medication due to the high cost of drugs. ${ }^{7}$ Most countries are facing escalating health care expenditures. Escalating costs and affordability of medicine for both governments and patients has become a global challenge. In an era of rapidly rising health care costs, generic medicines provide a less expensive alternative to branded medicines. Generic drugs are an alternative to brand drugs in many countries including the United States, Germany and developing countries like India. ${ }^{8}$ The use of generic medicines contributed to substantial savings in medicine expenditure. ${ }^{9}$ In addition to reducing the overall health care expenditure, use of generic medicine can reduce patients out of pocket costs and has been shown to improve adherence. ${ }^{10}$

In our study, the average number of drugs per prescription was 3.16. In a similar study, Meena et al reported the number of drugs per prescription $2.96 .{ }^{11}$ The lower number of drugs noticed is a welcome sign and needs to be encouraged. There may be an increase in compliance, lower cost of therapy and lower risk of drug interactions when a lesser number of drugs were prescribed.

Figure 1 shows the average number of drugs used in each prescription was two drugs per prescriptions $78.87 \%$ and three drugs per prescriptions $22.22 \%$. Thus, each prescription contains an intranasal corticosteroid, or nasal decongestant, an antihistamine or leukotrienes antagonist on average prescribed drugs which are compared to other studies previously we conducted Thandu et al reported, this drugs block the action of histamine and released on exposure to allergens. ${ }^{12}$ They also used to relieve hay fever symptoms such as sneezing, runny nose, and other nasal symptoms. Figure 2 shows the total cost of the prescribed drugs per prescriptions was in the range of Rs. 251-300 in $43 \%$ and in $18 \%$ it was Rs. 301-350. The duration of treatment for allergic rhinitis was 15 or 20 days which is long and also intranasal corticosteroids were which increases the cost per prescription. This was compared to the previous study, by Kozam et al in which the cost-effectiveness of intranasal corticosteroids versus oral antihistamines was assessed in three randomized controlled trials on the treatment of allergic rhinitis. ${ }^{13}$

Patient knowledge about the drug use (Table 1) in this study, out of 200 patients $37 \%$ of allergic rhinitis patients knew the correct dosage of the prescribed drugs while $63 \%$ were not aware, similar study done by Rajasekaran et al, showed a poor knowledge about the drug use in treatment of allergic rhinitis. ${ }^{14}$ Thus, in this study we documented lower patients' knowledge regarding the prescribed drugs. The value of nasal decongestants was realized by many patients however role of antihistamines, leukotrienes antagonists and nasal steroids was only understood by the educated class of patients.

During the study, all the drugs were prescribed by brand name and no drugs were prescribed by generic name. This finding suggests the popularity of brands and the influence of the pharmaceutical companies on the clinicians. However, it is recommended to prescribe by generic name, as it leads to the rational use of drugs and provides a cost-effective therapeutic option.

\section{CONCLUSION}

Result from this research showed that in majority of participants drugs were prescribed two to three drugs, per prescription cost was high because all the drugs prescribed by branded name and no drugs were prescribed by generic (chemical) name. They didn't know about generic medicine. Reduction in cost of drug will improve compliance, which will indirectly reflect in good response to drug therapy.

\section{Funding: No funding sources Conflict of interest: None declared \\ Ethical approval: The study was approved by the Institutional Ethics Committee}

\section{REFERENCES}

1. Gupta SK. Proposed Pharmacoeconomics Guidelines for India (PEG-I). IPSOR India. Second International Conference of Pharmacoeconomics and Outcomes Research; 2013: 79-100.

2. Ahuja J, Gupta M, Gupta AK, Kohli K. Pharmacoeconomics. Natl Med J India. 2004;17:803.

3. Trask L. Pharmacoeconomics: Principles, methods, and applications. In: Di Piro JT, Talbert RL, Yee GC, Matzke GR, Wells BG, Posey L, eds. Pharmacotherapy: a pathophysiologic approach. 8th ed. New York, NY: McGraw-Hill; 2011.

4. Atal S, Ata S, Deshmankar B, Nawaz SA. Cost analysis of commonly used drugs under price control in India: assessing the effect of drug price control 
order on brand price variation. Int J Pharm Pharm Sci. 2016;8(4):315-21.

5. Bousquet J, Khaltaev N, Cruz AA, Denburg J, Fokkens WJ, Togias A, et al. Allergic Rhinitis and its Impact on Asthma (ARIA) 2008 update (in collaboration with the World Health Organization, GA(2)LEN and AllerGen). Allergy. 2008;63:8-160.

6. Cruz AA, Popov T, Pawankar R, Annesi-Maesano I, Fokkens W, Kemp J, et al. Common characteristics of upper and lower airways in rhinitis and asthma: ARIA update, in collaboration with GA(2)LEN. Allergy. 2007;62 (84):1-41.

7. Babar ZU, Stewart J, Reddy S, Alzaher W, Vareed P, Yacoub N, et al. An evaluation of consumers knowledge, perceptions and attitudes regarding generic medicines in Auckland. Pharma World Sci. 2010;32(4):440-8.

8. Thomas R, Vitry A. Consumers perception of generic medicines in community pharmacies in Malaysia. South Med Rev. 2009;2(2):20-3.

9. Andersson K, Bergstrom G, Petzold MG, Carlstern A. Impact of a generic substitution reform on patients and society sexpenditure for pharmaceuticals. Health Policy. 2007;81:376-84.

10. Shrank WH, Hoang T, Ettner SL, Glasssman PA, Nair K, De Lapp D, et al. The implications of choice;
Prescribing generic or preferred pharmaceuticals improves medication adherence for chronic conditions. Arch Intern Med. 2006;166:332-7.

11. DS Pearlman. Pathophysiology of the inflammatory response. J Allergy Clin Immunol. 2001;104(4):1327.

12. Thandu SKG, Kumar R, Patil VG, Dighe D, Lalan HN, Singh A. Drug utilization pattern in upper respiratory tract infections in ent outpatient department of tertiary care hospital. Indian J Appl Res. 2014;4(5):484-7.

13. Kozma CM, Schulz RM, Sclar DA, Kral KM, Mackowiak JI. A comparison of costs and efficacy of intranasal fluticasone and terfinaine tablets for seasonal allergic rhinitis. Clin Ther. 1996;18:334-46.

14. Rajasekaran V, Ghosh P. Knowledge, attitude and practice about allergic rhinitis in a rural population, Kancheepuram district, Tamil Nadu. Int J Otorhinolaryngol Head Neck Surg. 2018;4(1):15962.

Cite this article as: Thandu SKG, Kumar ANV, Kunkulol RR. Pharmacoeconomics of allergic rhinitis drugs treatment in tertiary care hospital. Int J Basic Clin Pharmacol 2019;8:2313-6. 